\title{
Basic Characteristics of Coal Gangue in a Small-Scale Mining Site and Risk Assessment of Radioactive Elements for the Surrounding Soils
}

\author{
Dun $\mathrm{Wu}^{1,2}$, Yuanyuan Wang ${ }^{3}$, Meichen Wang ${ }^{2,4}$, Chao Wei ${ }^{2}$, Guangqing $\mathrm{Hu}{ }^{1,2, *}$, Xiaoli He ${ }^{5, *}$ and Wei Fu ${ }^{6}$ \\ 1 School of Earth and Space Sciences, University of Science and Technology of China, Hefei 230026, China; \\ wudun@ustc.edu.cn \\ 2 Exploration Research Institute, Anhui Provincial Bureau of Coal Geology, Hefei 230088, China; \\ mcwang16@163.com (M.W.); 2017170534@mail.hfut.edu.cn (C.W.) \\ 3 Anhui Province Engineering Laboratory for Mine Ecological Remediation, School of Resources and \\ Environmental Engineering, Anhui University, Hefei 230601, China; x19201043@stu.ahu.edu.cn \\ 4 School of Resources and Environmental Engineering, Hefei University of Technology, Hefei 230009, China \\ 5 Biology Engineering Institute, Hefei Vocational and Technology College, Hefei 238000, China \\ 6 CCTEG Shengyang Reserach Institute, Shengyang 110000, China; 17120089016@xust.edu.cn \\ * Correspondence: hgq18855146880@mail.ustc.edu.cn (G.H.); hxl@htc.edu.cn (X.H.)
}

check for updates

Citation: Wu, D.; Wang, Y.; Wang, M.; Wei, C.; Hu, G.; He, X.; Fu, W. Basic Characteristics of Coal Gangue in a Small-Scale Mining Site and Risk Assessment of Radioactive Elements for the Surrounding Soils. Minerals 2021, 11, 647. https://doi.org/ $10.3390 / \min 11060647$

Academic Editors: Monika

J. Fabiańska, Magdalena

Misz-Kennan and Justyna Ciesielczuk

Received: 21 April 2021

Accepted: 14 June 2021

Published: 18 June 2021

Publisher's Note: MDPI stays neutral with regard to jurisdictional claims in published maps and institutional affiliations.

Copyright: (c) 2021 by the authors. Licensee MDPI, Basel, Switzerland. This article is an open access article distributed under the terms and conditions of the Creative Commons Attribution (CC BY) license (https:// creativecommons.org/licenses/by/ $4.0 /)$.
Abstract: The accumulation/improper treatment of coal gangue will not only lead to waste of land, but also cause environmental pollution. Especially the impact of radioactive elements on the surrounding ecological environment is widely concerned by many scholars. In this study, the concentration of radioactive elements (uranium (U) and thorium (Th)) of small-scale coal gangue mining site and surrounding soil in the northern region of Xieqiao coal mine were tested, the material composition of coal gangue was analyzed via XRF and XRD, the modes of occurrence of $U$ and Th elements were investigated, and their potential ecological risks and ecological effectiveness were evaluated. The results show that the clay minerals with high content in coal gangue are the key minerals for the adsorption of uranium and thorium in coal gangue. The specific activity of two radioactive elements ( $U$ and $T h$ ) in soil is much lower than that of coal gangue. With the increase of the distance from the soil collection point to the gangue piles and the depth of the soil profile, the specific activities of the two radioactive elements decrease gradually. On the basis of the concentration curve, the range of the radioactive contamination halo of gangue piles is limited $(\leq 30 \mathrm{~m})$, speculating qualitatively that the gangue dump has no significant influence on the radioactivity of the surrounding water. The modes of occurrence of $U$ and Th in coal gangue and soil are altered. According to the index of geo-accumulation, Th is easier to accumulate in soil environment, but $T h$ and $U$ pollution in soil is not obvious. In contrast to $U$ element, the active state of Th element in soil is generally affected by exogenous (coal gangue) export, which may have a potential environmental effects. This study provides a research idea for the investigation of radioactive element pollution to the surrounding soil in small-scale coal gangue plies.

Keywords: coal gangue; mineral composition; radioactive element; the modes of occurrence

\section{Introduction}

Coal is the main energy used in China at present, accounting for about $70 \%$ of one-time energy consumption in China [1]. Coal mining and washing will produce a large amount of coal gangue. In 2019, the output of coal gangue in China is 470 million tons, and the comprehensive utilization rate is only $58.5 \%$. Therefore, it is a new trend to carry out coal gangue reduction and resource utilization in China in the future to integrate and refine coal gangue on the basis of fully carrying out harmless research.

The massive accumulation of coal gangue on the surface will bring a series of problems, such as occupying land resources, polluting water and soil, destroying ecosystems, etc. 
It also contains a variety of toxic and harmful substances, such as pyrite and pyrrhotite and other metal sulfides, heavy metal elements, polycyclic aromatic hydrocarbons, and some radioactive substances, etc. Coal gangue often contains radioactive elements such as ${ }^{226} \mathrm{Ra},{ }^{232} \mathrm{Th}$ and ${ }^{40} \mathrm{~K}$ [2]. When piled in the open air, the radioactive elements easily diffuse and migrate to the surrounding environment under the action of precipitation leaching, weathering, and leakage, and then enter the water body along with infiltration and surface runoff. Thereby increasing the concentration of natural radioactive elements in the environment and possibly causing radioactive pollution. At present, the research on radioactive environment mainly focuses on coal gangue [3,4], soil [5], water body [6,7], and so on.

In recent years, scholars in China and abroad pay close attention to the potential ecological risks of radioactive elements in coal gangue. Zhou et al. [8] studied the environmental geochemical characteristics of trace elements and natural radioactive elements around coal gangue piles, and found that $\mathrm{Cu}, \mathrm{Ni}$, and $\mathrm{Pb}$ were enriched in soybeans in the study area, and natural radioactive elements would increase the health risks of respiratory system. Habib et al. [9] aiming to coal and coal-fired residues in coal-fired power plants carried out radioactivity assessment, and found that the radioactivity of coal-fired residues is highly polluted, which may pose a radiation threat to the local environment. Habib et al. [10] evaluated the distribution of natural radionuclides and their potential radioactive risks in the surrounding soil of coal-fired power plants. The results indicated that coal-fired power plants had no significant influence on the radioactive concentration in the surrounding soil. Bohdan et al. [11] reported the geochemistry and environmental impact of neutral drainage from an uraniferous coal waste pile, investigated an impact of former coal waste pile on local drainage, and finally concluded the amount of uranium element in sediments decreased with the distance from the plie. Noli et al. [12] monitored the seasonal changes of natural radionuclides in lake sediments and water of the lignite mining area in northwest Greece, and found that most radionuclides have significant differences between cold and warm periods, and the accumulation amount was related to the distance from pollution sources.

Nowadays, radioactive pollution, microbial pollution, and chemical pollution are called the three major factors that affect the quality of water environment, and radionuclides have become an important index of water environment quality standard. Chalupnik et al. [13] investigated radium radionuclides in the water discharged from the upper reaches of Silesia River, and the results showed that radium was released into the river containing mine wastewater, causing pollution of bottom sediments and riverbanks. Luneva [14] reported the concentration activity of radionuclides in surface water, bottom sediments, and aquatic organisms around the Nyman River around the NPP nuclear power plant under construction at the global background level. Carvalho et al. [7] determined uranium radionuclides in water near a uranium mine in Portugal. The results showed that the concentration of uranium radionuclides in water and suspended solids increased due to the drainage of tailings pond.

Compared with previous studies, this study pays more attention to the analysis of the specific scientific problem. In this study, the scale of investigated site is small, and the coal gangue piles up together to form several different sizes of coal gangue piles. The coal gangue site is close to the surrounding water body, with the maximum horizontal distance not exceeding $50 \mathrm{~m}$ and the minimum horizontal distance only $20 \mathrm{~m}$; many aquaculture ponds can be seen on the water surface, in which aquatic products such as fish, shrimp, shellfish, and river crabs are cultured. The key scientific problem to be solved in this study is whether the close stacking of coal gangue will produce radioactive element radiation to the surrounding water. Considering that complex factors such as water circulation, wind speed, and atmospheric rainfall are bound to have different influences on the research results, a practical research scheme is formulated to solve the problems from qualitative to semi-quantitative perspectives. We selected a representative path from the gangue pile site, and collected soil samples at different depths along this path until the site contacted 
the water surface edge of the collapse area, and analyzed the variation regulation of concentration and the modes of occurrence for radioactive elements in soil along this path, so as to deeply understand the influence radius of radioactive elements in gangue from the gangue pile site, and qualitatively judge whether the gangue has radioactivity in the surrounding water.

With the aim of the small-scale coal gangue site in the northern area of Xieqiao coal mine, the following main contents are completed. (1) Identification of the basic material composition of coal gangue (especially its mineral types) and the concentration of radioactive elements ( $\mathrm{U}$ and $\mathrm{Th}$ ); (2) whether the present concentration and occurrence form of radioactive elements ( $\mathrm{U}$ and $\mathrm{Th}$ ) in coal gangue are related to the surrounding soil; (3) what changes have taken place in the concentration and occurrence forms of radioactive elements in soil with depth and distance, and what are the main factors affecting them; (4) through in-depth data analysis, find out the influence range of coal gangue stacking on radioactive elements in surrounding soil, and then qualitatively judge whether it will affect surrounding water. This study is of great significance to the research and treatment of radioactive pollution of coal gangue.

\section{Materials and Methods}

\subsection{Physical Geography}

The study area is located in the Huainan coalfield in the north of Anhui Province, which is an important energy base in the east of China (Figure 1a,b). It belongs to a warm temperate semi-humid monsoon climate zone, which is dry and cold in winter and rainy in summer. The research area is located in the coal gangue yard $1.5 \mathrm{~km}$ north of Xieqiao coal mine in Huainan coalfield. Based on the analysis of the image data in Figure 1h, the size of the coal gangue site is about $960 \mathrm{~m}^{2}$. In view of the fact that the coal gangue covers the soil, the rainwater washes the surface of the gangue pile under the action of rainfall, and penetrates into the gangue pile. Through the process of physical-chemistry, the gangue particles can be entrained along the soil surface runoff, thus it is possible to increase the level of radioactive elements in the topsoil around the gangue pile. Due to the accumulation of coal gangue on the soil surface, under the action of rainfall leaching, the easily-contained components in the coal gangue are dissolved and taken away by the seepage water in the process of the atmospheric precipitation infiltrating into the interior of the coal gangue pile. After these physical and chemical actions of the seepage water, the seepage water along the surface runoff will cause a certain degree of pollution to the soil environment around the gangue pile and cause local enrichment of radioactive elements in the soil. In addition, the gangue particles may be deposited on the soil surface under the action of weathering agent. There are farmland and a water system in the vicinity of the coal gangue pile (Figure $1 \mathrm{c}, \mathrm{d}, \mathrm{j}$ ). Therefore, this study aimed to explore whether the surrounding soil will be polluted by radioactive elements when coal gangue was piled up and to preliminarily determine the extent of the contamination halo (the inflection point of element specific activity in the profile). The ecological risk assessment of radioactive elements was carried out by the analysis of their modes of occurrence, and then the influence of gangue piling on the water-accumulating area was indirectly evaluated. This research has certain theoretical and practical significance. 


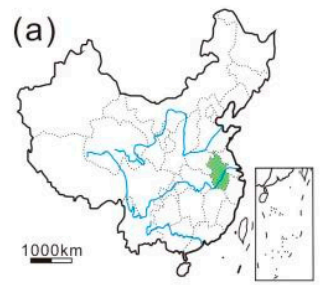

(b)
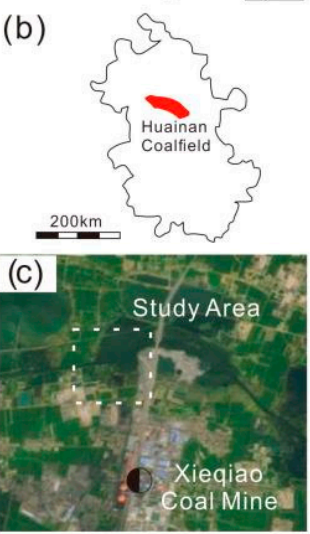

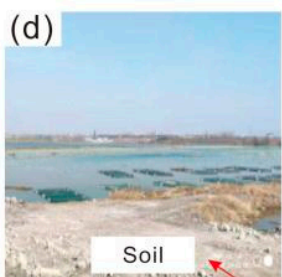

(e)
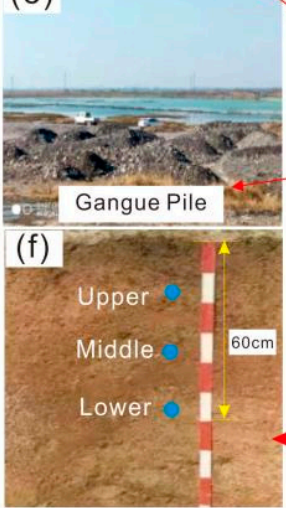
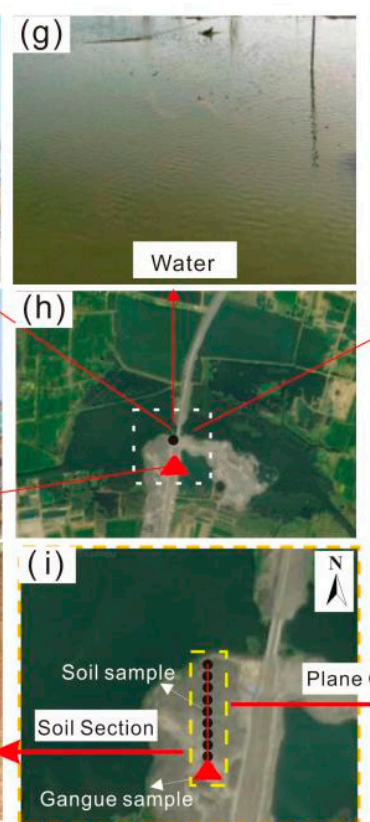

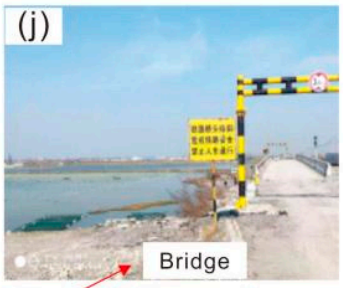

$(\mathrm{k})$

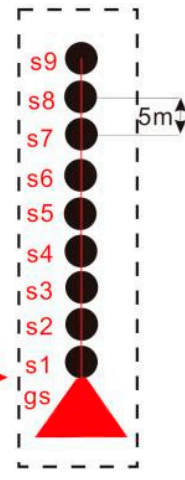

Figure 1. Location map of the study area and overview of sample collection. (a) The territory of China, and the green part is the province where the study area is located; (b) Huainan coalfield where the study area is located; (c) the study area is located to the south of Xieqiao coal mine; (d) sampling location—soil; (e) sampling position—coal gangue pile; (f) sampling interval of soil profile; (g) surrounding water bodies; $(\mathbf{h})$ enlarged view of the location of the study area; (i) enlarged layout of sampling points for coal gangue and soil; (j) roads around the study area; (k) enlarged layout of coal gangue and soils sampling points.

\subsection{Sample Collection}

After a regional investigation, it was known that the coal gangue mainly comes from the nearby Xieqiao coal mine, which is mined underground. The gangue is transported from the underground to the surface, and then transported by truck to the gangue dump. In the course of transporting coal gangue, there is no interference of other substances. Three coal gangue samples (parallel samples, numbered gs-1, gs-2 and gs-3, Figure 1e) were collected at the bottom of the coal gangue dump, and sealed and stored in fresh-keeping bags for subsequent treatment. Through the actual reconnaissance of the research site, we recognized the distribution of soil around coal gangue, for example, some surface soil was hardened, which increased the difficulty of sampling. Therefore, we chose a path a relatively long distance from the gangue dump to the surrounding water body and relatively fresh surface soil to collect. All soil samples were collected on one section. The distance between soil samples and the water body was different, but the distance between the coal gangue dump and the water body was about $50 \mathrm{~m}$. According to the investigation of previous studies, the collection of soil samples, in addition to the collection of surface soil, also needs to collect and analyze the samples of middle and deep soil $(40-60 \mathrm{~cm})$. Only in this way could we objectively reflect whether the radioactive elements in the soil were affected by the gangue dump. Therefore, nine soil profile sampling points (sampling interval of $5 \mathrm{~m}$, sample numbers s1, s2, s3...s8 and s9) were set at 5, 10, 15...40 and $45 \mathrm{~m}$ away from the coal gangue pile, respectively. The coal gangue was collected in three layers from top to bottom (Figure 1f), with $2 \mathrm{~kg}$ of soil samples collected from each layer and 27 soil samples collected in total (Figure $1 \mathrm{~h}$ ).

\subsection{Sample Pretreatment}

Coal gangue samples were naturally air-dried and pressed into round pieces with a diameter of $32 \mathrm{~mm}$ and an outer diameter of $10 \mathrm{~mm}$. After the samples were pressed, the remaining samples were manually ground to 200 mesh size to be measured. The 
large-particle stones and plant roots contained in the collected soil samples were manually remove, a proper amount of the original samples for each sample was reserved, and the rest were placed in the room for natural air drying and storage for testing. Coal gangue and soil samples to be tested were manually ground into 200 mesh in agate mortar, then packed with special sample paper bags, dried in a drying oven at $105^{\circ} \mathrm{C}$, dried for $24 \mathrm{~h}$, taken out and cooled to normal temperature in a dryer, and packed in sealed plastic bags for microwave digestion and element concentration test.

\subsection{Test Methods}

The experimental contents of this study mainly included the substance composition test (XRD and XRF) of coal gangue and the determination of the concentration and occurrence form of radioactive elements ( $U$ and $T h$ ) in coal gangue and soil. The purpose of each experiment and the logical relationship between them are shown in Figure 2.

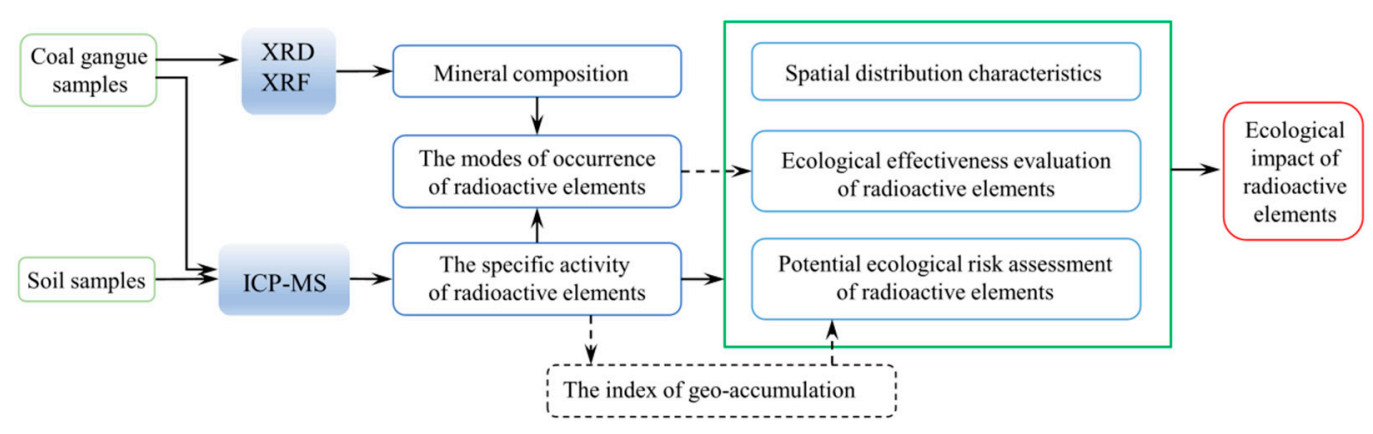

Figure 2. The experimental flow chart of this study. XRD: X-ray diffraction; XRF: X-ray fluorescence; ICP-MS: Inductively coupled plasma mass spectrometry.

\subsubsection{X-Ray Fluorescence Spectroscopy (XRF)}

The instrument used for XRF analysis of 3 coal gangue samples in this study was XRF-1800 of SHIMADZU Company, Japan. Rh target for X-ray tube, tube pressure-60 KV (Max), detection element range-4(Be)-92(U), detection concentration range- $-10^{-6}-100 \%$, minimum analysis area diameter-250 $\mu \mathrm{m}$. The main purpose of this experiment was to obtain the content of major elements in coal gangue.

\subsubsection{X-Ray Diffractometer (XRD)}

The experimental instrument used for $\mathrm{XRD}$ analysis of 2 coal gangue samples was an X-ray diffractometer of the $X^{\prime}$ Pert PRO type manufactured by PHILIPS. Experimental parameters included tube pressure of $60 \mathrm{KV}$ (Max), and X-ray tube current of $55 \mathrm{~mA}$. The main flow is as follows: Firstly, $20 \mathrm{~g}$ coal gangue sample was selected, grinded, crushed, and sieved (100 Mesh). After drying, a powder solid sample was obtained, and then the sample was put into a rectangular resonance cavity in the $\mathrm{X}$-ray diffractometer. The scanning range was $2 \theta=10^{\circ}-70^{\circ}$, the step distance was $0.1^{\circ}$, and the scanning speed was $2^{\circ} / \mathrm{min}$. The mineral composition of coal gangue could be obtained by this experiment.

\subsubsection{Inductively Coupled Plasma Mass Spectrometry (ICP-MS)}

The concentrations of radioactive elements ( $U$ and $T h)$ in coal gangue and soil were measured using the $\mathrm{X}$-series II ICP-MS developed by Thermo Fisher Scientific Company. The main experimental procedure is as follows: Firstly, the fresh sample of $2 \mathrm{~g}$ was grinded, crushed, and sieved (200 Mesh) to obtain the powder solid sample. Then the solid sample was pretreated by heating with electric heating plate, and was tested on ICP-MS after constant volume $(25 \mathrm{~mL})$. Two soil standard samples (GBW07401 and GBW07402) were set up for the experiment under the same experimental conditions. Sample analysis and testing strictly complied with the Quality Assurance Specification for Radioactive Mineral Geological Analysis and Testing Laboratory (EJ/T 751-2014), the detection limits of element 
analysis method were in line with the requirements of the standards, and there was no obvious system error. The actual mass of the sample could be obtained by multiplying the mass fraction and the volume of the sample by ICP-MS. According to the radioactivity calculated by mass conversion, the radioactivity per gram of ${ }^{238} \mathrm{U}$ is $1.23 \times 10^{4}$, and that of ${ }^{232} \mathrm{Th}$ is $4.05 \times 10^{3}$, then the specific activity of the tested sample can be calculated.

\subsubsection{Sequential Chemical Extraction Procedure}

In this study, a sequential chemical extraction procedure which can extract and partition into five chemical forms [15] was used to describe the modes of occurrence for radioactive elements in coal gangue and soil samples. A detailed experimental procedure has been documented in $\mathrm{Hu}$ et al. [16].

\subsection{Cumulative Index Method}

The index of geo-accumulation ( $\left.\mathrm{I}_{\text {geo }}\right)$ is also known as the Muller index. The index was developed by the German scientist Muller [17] and was used as a quantitative index of the extent of heavy metal pollution in European sediments and other materials in the late 1960s. The $I_{\text {geo }}$ not only considers the influence of background value caused by natural geological processes, but also pays attention to the influence of human activities on heavy metal pollution. Hence, the $I_{\text {geo }}$ not only reflects the natural distribution of heavy metals, but also can reflect the impact of human activities on the environment, thus is an important parameter to distinguish the impact of human activities.

$$
I_{\text {geo }}=\log _{2}\left(\frac{C_{n}}{K \times B_{n}}\right)
$$

where $C_{n}$ is the concentration of element $n$ in sediments. The concentration of radioactive elements in this study was expressed in units of specific activity $(\mathrm{Bq} / \mathrm{kg}) ; \mathrm{B}_{\mathrm{n}}$ is the soil background value of element $n$, this unit is consistent with $C_{n} ; \mathrm{K}$ is the correction coefficient taken to consider the change of background value caused by rock differences in different places. This coefficient is employed to characterize sedimentary characteristics, rock geology, and other associated effects. In this study, $\mathrm{K}=1.5$. In the process of previous evaluation, in addition to considering the human pollution factors and environmental geochemical background values, the factors of background value changes caused by natural diagenesis have often been ignored by the researchers. However, the index of geological accumulation method takes this factor into account and makes up for the deficiency of other evaluation methods.

More generally, the higher the index of geo-accumulation, the higher the enrichment of this element in the sediments studied. See Table 1 for the pollution degree of $\mathrm{I}_{\text {geo }}$.

Table 1. Classification of the pollution degree of the index of geo-accumulation ( $\left.\mathrm{I}_{\text {geo }}\right)$.

\begin{tabular}{cccccc}
\hline I $_{\text {geo }}$ & Grade & Contamination Degree & I $_{\text {geo }}$ & Grade & Contamination Degree \\
\hline$<0$ & 0 & pollution-free & $3-4$ & 4 & Strong pollution \\
$0-1$ & 1 & Mild to moderate pollution & $4-5$ & 5 & Strong to serious pollution \\
$1-2$ & 2 & Moderate pollution & $>5$ & 6 & Serious pollution \\
$2-3$ & 3 & Moderate to strong pollution & & & \\
\hline
\end{tabular}

\section{Results and Discussion}

\subsection{Mineral Composition of Coal Gangue}

Different minerals have different sorption capacity for U and Th. Generally speaking, from opal, mica, clay minerals to iron oxides, the sorption capacity of $U$ on mineral surfaces increases in turn [18], and the sorption capacity of illite and montmorillonite on $U$ and $T h$ in clay minerals is much higher than that of kaolinite. Therefore, analyzing the mineral composition of coal gangue is of great significance for judging the sorption and release ability of coal gangue to $\mathrm{U}$ and Th. 
The chemical composition of coal gangue will change with the lithology and mineral composition of coal seam, and the heterogeneity is obvious. The mineral composition of coal gangue in the Huainan mining area is mainly kaolinite and quartz, with a small amount of illite, calcite, pyrite, etc., which is influenced by factors such as surface differentiation, leaching and stacking time. XRF analysis of coal gangue (Table 2) shows that the average content of $\mathrm{SiO}_{2}$ in the main chemical components of coal gangue is relatively high, with a content of $52.41 \%$, followed by $\mathrm{Al}_{2} \mathrm{O}_{3}$ with a content of $25.88 \%$. The ratio of $\mathrm{Al}_{2} \mathrm{O}_{3} / \mathrm{SiO}_{2}$ in the sample is less than and close to 0.5 , so the coal gangue in this mining area is mainly clay mineral (kaolinite). The average content of $\mathrm{CaO}$ in coal gangue is $10.15 \%$, which is related to calcite in coal gangue. The average content of $\mathrm{Fe}_{2} \mathrm{O}_{3}$ in coal gangue is 7.32\%, and there are some differences among different coal gangue samples, mainly due to the oxidation reaction of coal gangue in different degrees due to long-term weathering. Other chemical components, such as $\mathrm{K}_{2} \mathrm{O}, \mathrm{TiO}_{2}, \mathrm{MgO}$, and $\mathrm{Na}_{2} \mathrm{O}$, are low in content, generally about $1 \%$, and mainly exist in the form of potash feldspar or mica, rutile and albite in coal gangue [19]. The XRD analysis results of two coal gangue are consistent with XRF, which shows that the diffraction peaks of quartz and kaolinite are obvious (Figure 3), and the intensity of diffraction peaks is high. The results are consistent with those of Bu et al. [20]. The clay minerals are mainly kaolinite, including calcite, dickite, and siderite.

Table 2. Proportion of major components of coal gangue.

\begin{tabular}{cccccccccc}
\hline \multirow{2}{*}{ Sample } & \multirow{2}{*}{ Number } & \multicolumn{7}{c}{ Percentage (\%) } \\
\cline { 3 - 10 } & & $\mathbf{S i O}_{\mathbf{2}}$ & $\mathbf{A l}_{\mathbf{2}} \mathbf{O}_{\mathbf{3}}$ & $\mathbf{F e}_{\mathbf{2}} \mathbf{O}_{\mathbf{3}}$ & $\mathbf{C a O}$ & $\mathbf{M g O}$ & $\mathbf{K}_{\mathbf{2}} \mathbf{O}$ & $\mathbf{N a}_{\mathbf{2}} \mathbf{O}$ & $\mathbf{T i O}_{\mathbf{2}}$ \\
\hline \multirow{2}{*}{ Coal } & $\mathrm{gs}-1$ & 52.27 & 26.12 & 8.23 & 9.05 & 0.87 & 0.74 & 1.35 & 0.99 \\
\multirow{2}{*}{ gangue } & $\mathrm{gs}-2$ & 52.4 & 25.8 & 7.27 & 10.22 & 0.81 & 0.84 & 1.23 & 1.04 \\
& $\mathrm{gs}-3$ & 52.55 & 25.73 & 6.45 & 11.18 & 1.01 & 0.92 & 0.83 & 0.91 \\
\hline \multicolumn{2}{c}{ Average } & 52.41 & 25.88 & 7.32 & 10.15 & 0.90 & 0.83 & 1.14 & 0.98 \\
\hline
\end{tabular}
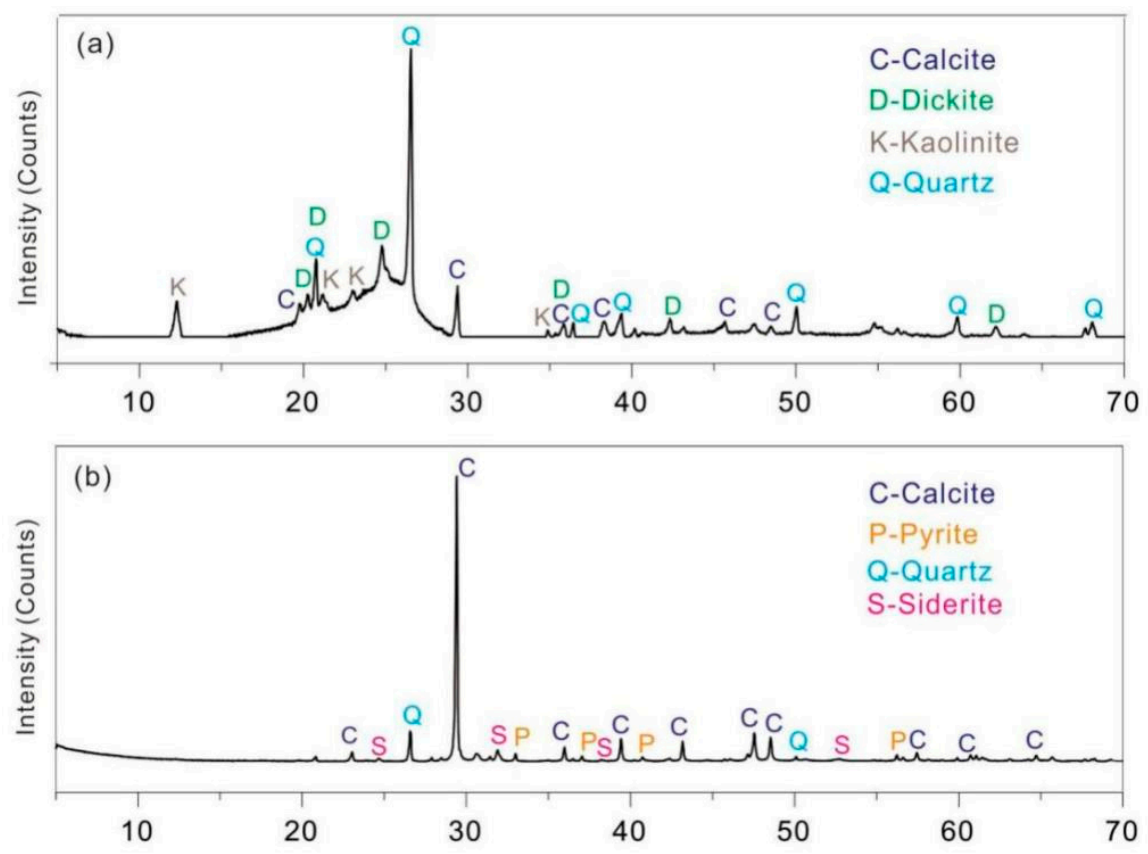

Figure 3. The XRD test results of coal gangue samples: (a) gs-1 sample; (b) gs-2 sample. The proportion is calculated by mass fraction.

The experimental test results of XRD and XRF are consistent with the research results of $\mathrm{Li}$ [21], but it is worth noting that the $\mathrm{CaO}$ content in coal gangue samples is relatively high (average 10.15\%), while the $\mathrm{CaO}$ content in coal gangue of adjacent coal mines (such 
as Dingji, Guqiao and Zhangji Coal Mines) is generally less than 2\% [21,22], which may be related to calcite along the structure in coal seam during coal formation. According to the mineral composition analysis of coal gangue, the clay mineral with high content in coal gangue is the key mineral for the sorption of $U$ and Th elements, and the existence of iron oxide in coal gangue has a positive effect on the sorption of $U$ and Th elements.

\subsection{Element Specific Activity Characteristics}

The concentration of radioactive elements in soil is analyzed via ICP-MS, and the calculated results of specific activity are shown in the Figure 4. It can be seen from Figure 4a that the distribution characteristics of ${ }^{238} \mathrm{U}$ specific activity of soil samples collected at different sampling points and different depths are the same. The specific activity of ${ }^{238} \mathrm{U}$ in soil is obviously lower than that of coal gangue, and the deeper the sampling depth, the lower the specific activity of ${ }^{238} \mathrm{U}$. This is consistent with the vertical profile of trace elements in the sediments of the Rambro River (northern Italy) by Marziali et al. [23]. The specific activity of ${ }^{238} \mathrm{U}$ in soil of different sampling points has no obvious regularity within a certain range. When the distance reaches a certain value, the radioactivity decreases gradually with the increase of distance. This is in line with Abiriga et al.'s finding that pollutants decrease with the increase of distance by taking the groundwater of municipal waste landfill as the research object [24].

It can be seen from the Figure $4 \mathrm{~b}$ that the specific activity of ${ }^{232} \mathrm{Th}$ in soil samples collected at different sampling points and depths shows different characteristics, but the overall law is the same. The ${ }^{232} \mathrm{Th}$ specific activity in soil is obviously lower than that of coal gangue, and the deeper the soil sampling depth, the lower the ${ }^{232} \mathrm{Th}$ specific activity. The specific activity of ${ }^{232} \mathrm{Th}$ in soil of different sampling points has no obvious regularity within a certain range. When the distance reaches a certain value, the radioactivity decreases gradually with the increase of distance. The upper and lower layers have inflection points at s5 $(25 \mathrm{~m})$, and the middle layer has inflection points at $\mathrm{s} 6(30 \mathrm{~m}) .{ }^{238} \mathrm{U}$ and ${ }^{232} \mathrm{Th}$ have certain impacts on the surrounding soil, but the pollution range is limited $(\leq 30 \mathrm{~m})$, and the specific activity of radioactive elements above $30 \mathrm{~m}$ will obviously decrease, without affecting the surrounding water body.
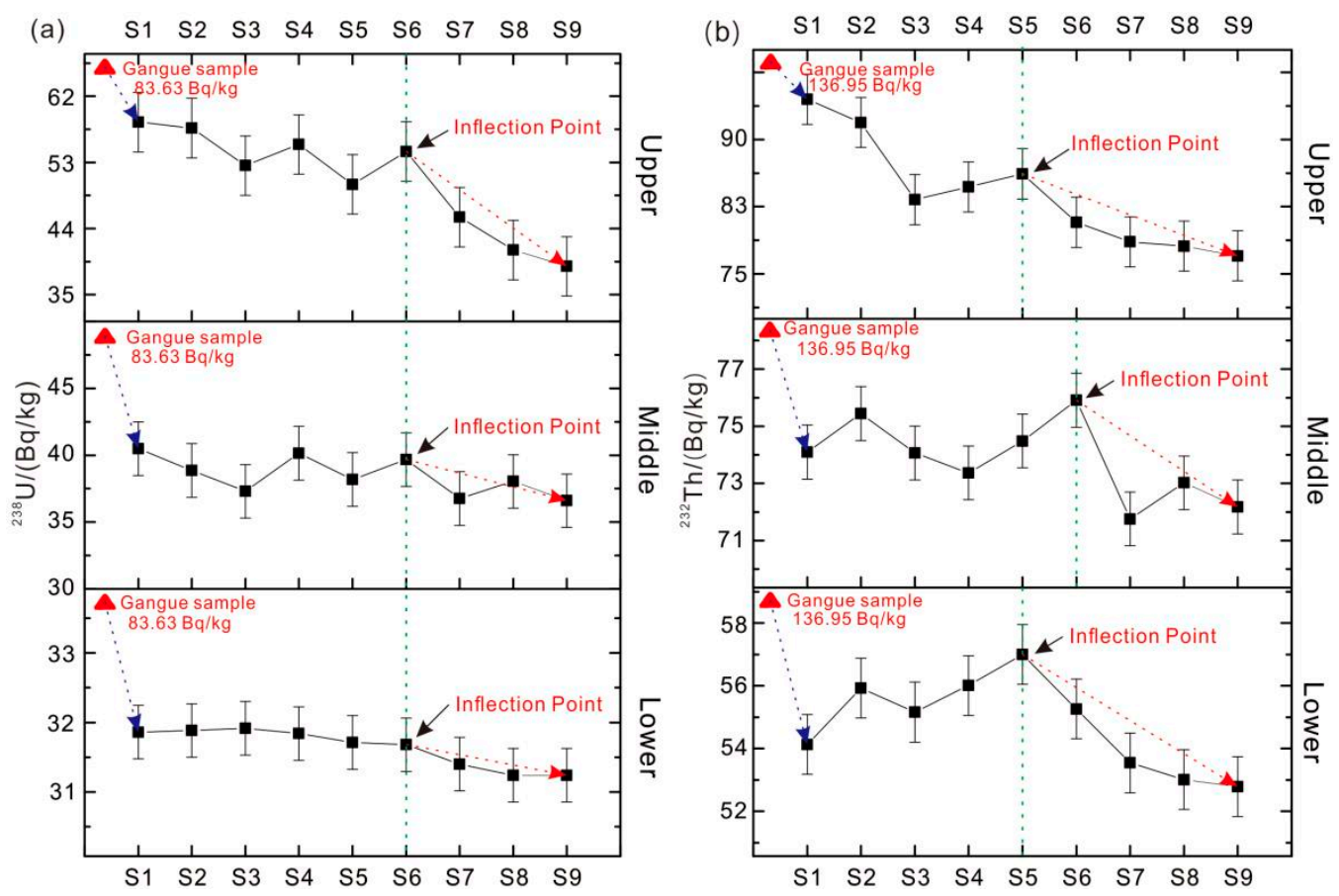

Figure 4. Specific activity of coal gangue and surrounding soil samples: (a) ${ }^{238} \mathrm{U}$; (b) ${ }^{232} \mathrm{Th}$. 


\subsection{The Modes of Occurrence}

The environmental impact and ecological effectiveness of radioactive element in coal gangue and soil do not depend on their total amount, but mainly on their easily activated forms (exchangeable and carbonate-bound) and potential active forms (organically bound and iron-manganese oxidized) [25]. Therefore, it is of great significance to analyze the modes of occurrence for $U$ and $T h$ in coal gangue and soil for understanding the potential environmental impact of soil radioactivity.

Table 3 presents the percentages of $U$ and Th elements with different modes of occurrence in the coal gangue and soil profile samples, indicating that the absolute value of data deviation of most samples is less than $10 \%$, and that of some samples is less than $20 \%$. There is no obvious artificial pollution and loss in the step-by-step chemical extraction experiment and the experimental analysis data is reliable.

Table 3. The modes of occurrence for $U$ and Th elements in coal gangue and soil profile samples (Unit: Bq/kg).

\begin{tabular}{|c|c|c|c|c|c|c|c|c|c|c|c|}
\hline \multirow{2}{*}{\multicolumn{2}{|c|}{ Sample }} & \multicolumn{5}{|c|}{$\mathrm{U}$} & \multicolumn{5}{|c|}{ Th } \\
\hline & & \multirow{2}{*}{$\begin{array}{c}\text { Exchangeable } \\
10.34\end{array}$} & \multirow{2}{*}{$\begin{array}{c}\text { Carbonate } \\
23.76\end{array}$} & \multirow{2}{*}{$\begin{array}{c}\begin{array}{c}\text { Fe-Mn } \\
\text { Oxide }\end{array} \\
8.34\end{array}$} & \multirow{2}{*}{$\begin{array}{c}\text { Organic } \\
12.34\end{array}$} & \multirow{2}{*}{$\begin{array}{c}\text { Residual } \\
45.22\end{array}$} & \multirow{3}{*}{$\begin{array}{c}\text { Exchangeable } \\
9.43 \\
13.45\end{array}$} & \multirow{3}{*}{$\begin{array}{c}\text { Carbonate } \\
7.84 \\
14.88\end{array}$} & \multirow{3}{*}{$\begin{array}{c}\begin{array}{c}\text { Fe-Mn } \\
\text { Oxide }\end{array} \\
21.01 \\
19.09\end{array}$} & \multirow{3}{*}{$\begin{array}{c}\text { Organic } \\
11.51 \\
9.32\end{array}$} & \multirow{2}{*}{$\begin{array}{c}\text { Residual } \\
50.21\end{array}$} \\
\hline Coal & gs-1 & & & & & & & & & & \\
\hline gangue & gs-2 & 8.37 & 28.39 & 12.09 & 18.34 & 32.81 & & & & & 43.26 \\
\hline \multirow{9}{*}{ Soil } & s3-1 & 3.25 & 25.47 & 7.20 & 63.22 & 0.86 & 10.21 & 11.45 & 30.95 & 10.82 & 36.57 \\
\hline & s3-2 & 4.27 & 28.76 & 13.56 & 45.23 & 8.18 & 8.68 & 17.56 & 25.76 & 8.56 & 39.44 \\
\hline & s3-3 & 2.03 & 35.81 & 12.34 & 46.19 & 3.63 & 8.03 & 8.77 & 30.32 & 10.5 & 42.38 \\
\hline & s6-1 & 9.39 & 33.24 & 2.12 & 50.32 & 4.93 & 7.21 & 12.35 & 24.27 & 4.63 & 51.54 \\
\hline & s6-2 & 6.67 & 35.74 & 8.98 & 44.21 & 4.40 & 5.35 & 10.42 & 15.62 & 13.32 & 55.29 \\
\hline & s6-3 & 5.35 & 45.12 & 7.21 & 42.17 & 0.15 & 10.35 & 15.43 & 19.34 & 8.26 & 46.62 \\
\hline & s9-1 & 4.89 & 23.13 & 12.31 & 50.48 & 9.19 & 11.74 & 9.75 & 12.11 & 4.18 & 62.22 \\
\hline & s9-2 & 8.27 & 26.76 & 9.92 & 45.69 & 9.36 & 5.77 & 6.32 & 20.32 & 9.14 & 58.45 \\
\hline & s9-3 & 7.54 & 30.34 & 3.18 & 40.12 & 18.82 & ND & 7.13 & 14.21 & 6.21 & 72.45 \\
\hline
\end{tabular}

\subsubsection{The Modes of Occurrence for U Element}

The modes of occurrence for $U$ element in coal is obviously affected by coal metamorphism and coal quality, and $U$ in low rank coal mainly contains organic matter (55\%) and silicate minerals (35\%) [26]. At present, there is little research on the occurrence form of $U$ in coal gangue. The modes of occurrence for $U$ element in the coal gangue samples (gs-1 and gs-2) (Figure 5) is similar to that of low rank coal, mainly in residue state (III) and carbonate bound state (II), accounting for $39.02 \%$ and $26.08 \%$ on average, followed by organic bound state (IV) and Fe-Mn oxidation (III). On the one hand, there are more clay and calcite minerals in the coal gangue samples; on the other hand, it may be related to the low metamorphic degree of the main coal seam in the study area [16].

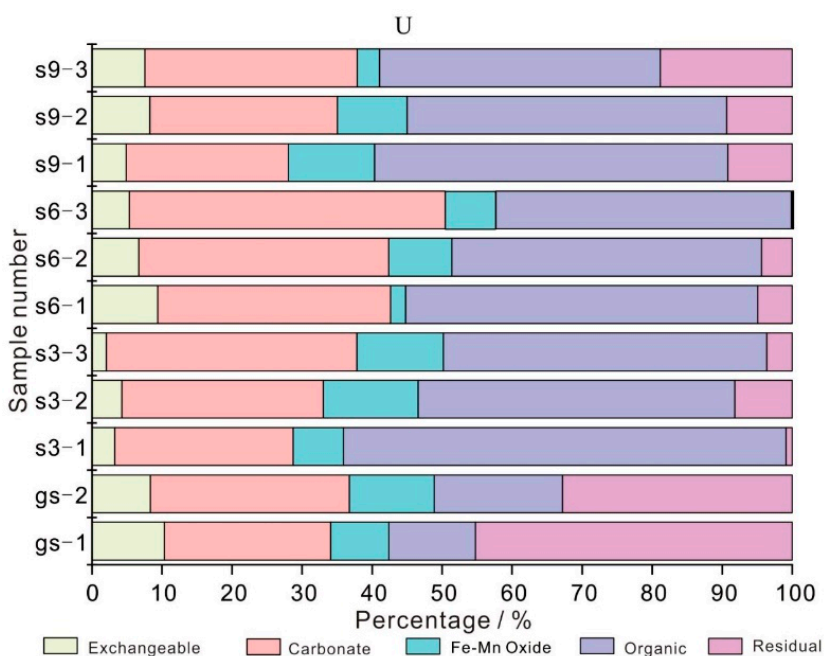

Figure 5. The modes of occurrence for U element in coal gangue and soil profile. 
Organic (IV) and carbonate-bound (II) are the main forms of U in three soil profile samples (s3, s6, and s9), accounting for $47.51 \%$ and $31.60 \%$ on average, respectively, followed by Fe-Mn oxidation (III) and residue (V). Figure 5 shows that the modes of occurrence for $\mathrm{U}$ element in three soil profile samples changes obviously with the distance of coal gangue and the sampling depth, which is mainly manifested as follows: (1) With the increase of sampling distance, the content of $U$ in exchangeable state (I) gradually increases (from $2.03 \%$ to $9.39 \%$ ); the content of organic bound (IV) gradually decreased (from $63.22 \%$ to $40.12 \%$ ). The change of other occurrence states is not obvious. (2) With the increase of sampling depth, the carbonate-bound (II) content of $\mathrm{U}$ in each soil profile showed a gradual increase trend, while the organic-bound (IV) content showed a gradual decrease trend and the change law of other occurrence states was not obvious.

The stacking of coal gangue has certain influence on the content of $U$ in the surrounding soil, and there is pollution from exogenous $U$ in every occurrence state of soil, which is closely related to the distance of coal gangue yard and the depth of soil [27]. U can migrate in soil by means of water-soluble, colloid, and clastic particles. The modes of occurrence for $\mathrm{U}$ in the three soil profiles is mainly organic (IV) and carbonate-bound (II), which means that $U$ mainly migrates in the form of water-soluble and organic colloid in the soil, and is affected by soil interception. The farther away from the pollution source, the smaller the input amount of $U$ in the downstream soil. At the same distance, the deeper the soil is buried, the U input of organic bound (IV) tends to decrease, but the U input of carbonate bound (II) tends to increase, which is mainly related to the deep precipitation mechanism of carbonate rocks.

\subsubsection{The Modes of Occurrence for Th Element}

At present, there are few studies on the modes of occurrence for Th in coal gangue, and most of them focus on metal ore and slag [28,29]. Th mainly exists in insoluble residues, which is more stable than $U$ element. This is mainly because Th mainly exists in insoluble residues and may exist in clay minerals such as silicates [30]. Figure 6 shows that the modes of occurrence for Th element in the coal gangue samples (gs-1 and gs-2) is mainly residue state (V) and Fe-Mn oxidation state (III), accounting for $46.74 \%$ and $20.05 \%$ on average, respectively, and the content of other occurrence states is equivalent (about 10\%). Therefore, Th in coal gangue mainly exists in clay minerals, which is consistent with previous analysis results [31].

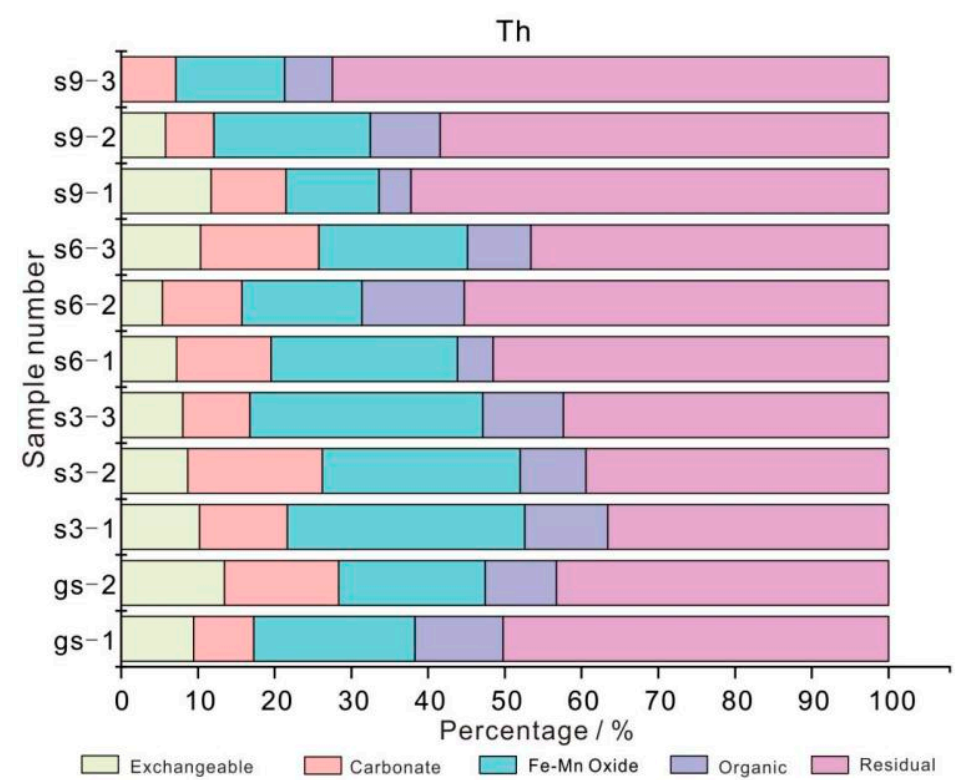

Figure 6. The modes of occurrence for Th element in coal gangue and soil profile. 
The modes of occurrence for Th element in the three soil profile samples (s3, s6, and s9) is consistent with that of coal gangue, with the residue state $(\mathrm{V})$ and Fe-Mn oxidation state (III) accounting for $51.66 \%$ and $21.44 \%$ on average, followed by carbonate bound state (II), exchangeable state (I) and organic state (IV). Compared with U, the modes of occurrence for Th element in three soil profile samples changes more obviously with the sampling distance and depth from coal gangue, which is mainly manifested as follows: (1) With the increase of sampling distance, the content of Th in exchangeable state (I) and Fe-Mn oxidized state (III) decreases gradually; the content in the residue (V) gradually increased (from $36.57 \%$ to $72.45 \%$ ). The change of other occurrence forms is not obvious. (2) With the increase of sampling depth, the content of residual state $(\mathrm{V})$ in each soil profile shows a gradual increasing trend, while the change of other occurrence states is not obvious.

To sum up, the piling of coal gangue has certain influence on the content of Th in surrounding soil, and is closely related to the distance of coal gangue yard and the depth of soil. The modes of occurrence for $\mathrm{U}$ in the three soil profiles is mainly residual state (V) and Fe-Mn oxidized state (III), and Th migrates in the form of water-soluble state and organic colloid, which is affected by soil interception. The farther away from the pollution source, the smaller the input amount of Th in the downstream soil. Under the condition of the same distance, the deeper the soil is buried, the less the input amount of the exchangeable state (I) is, and the proportion of the residual state (V) is correspondingly increased. The exchangeable state (I) plays a leading role in the migration of Th from the gangue pile to the soil.

\subsection{Potential Ecological Risk Assessment of Radioactive Elements}

In order to know whether the radioactivity in the soil around the coal gangue will affect the environment, the potential ecological risk of the collected samples was evaluated by using the index of geo-accumulation method. According to the research results of $\mathrm{Yu}$ et al. [32], the radioactive elements in China soil background are 38.5 and $54.6 \mathrm{~Bq} / \mathrm{kg}$ at ${ }^{238} \mathrm{U}$ and ${ }^{232} \mathrm{Th}$, respectively. The evaluation results of the index of geo-accumulation are shown in Table 4.

Table 4. Evaluation results by the index of geo-accumulation method.

\begin{tabular}{ccccc}
\hline Element & Number & Upper & Middle & Lower \\
\hline s1 & 0.0262 & -0.5124 & -0.8374 \\
s2 & 0.0066 & -0.5716 & -0.8361 \\
s3 & -0.1247 & -0.6306 & -0.8343 \\
& s4 & -0.0492 & -0.5245 & -0.8386 \\
& s5 & -0.1952 & -0.5969 & -0.8461 \\
& s6 & -0.0739 & -0.5417 & -0.8479 \\
& s7 & -0.3270 & -0.6515 & -0.8643 \\
& s8 & -0.4727 & -0.6021 & -0.8738 \\
& s9 & -0.5512 & -0.6580 & -0.8738 \\
\hline s1 & s2 & 0.2061 & -0.1457 & -0.5813 \\
& s3 & 0.1661 & -0.1235 & -0.5324 \\
& s4 & 0.0241 & -0.1462 & -0.5530 \\
& s5 & 0.0485 & -0.1578 & -0.5303 \\
& s6 & 0.0733 & -0.1393 & -0.5041 \\
& s7 & -0.0204 & -0.1160 & -0.5503 \\
& s8 & -0.0596 & -0.1850 & -0.5976 \\
& s9 & -0.0685 & -0.1636 & -0.6127 \\
& & -0.0887 & -0.1778 & -0.6190 \\
\hline
\end{tabular}

Table 4 indicates that the index of geo-accumulation of most soil samples is less than 0 , which indicates that most soil samples in the study area are not polluted; there is a small number of samples whose the index of geo-accumulation is greater than 0 but less than 1 , and this part of soil samples is slightly to moderately polluted. The index of geo- 
accumulation for Th is slightly larger than that of $U$, which indicates that the content of Th is easier to accumulate in the environment. There are slight differences between the two different radioactive elements, but their characteristics are the same in the soil samples of different depths. That is to say that the deeper the depth is, the smaller the index of geo-accumulation is, the smaller the external influence is.

\subsection{Ecological Effectiveness Evaluation of Radioactive Elements}

According to Martínez-Aguirre et al. [33], soil medium is the key link to communicate the release and migration path of $U$ and Th elements in coal gangue and water body. The ecological effectiveness evaluation of radioactive elements in soil is helpful to analyze whether the coal gangue pollutes the surrounding water body with radioactive elements. It is generally believed that exchangeable form (I) and carbonate bound form (II) have strong environmental activity and are easily absorbed by organisms. Fe-Mn oxidized state (III) and organic binding state (IV) usually show certain activity with the change of oxidation-reduction conditions of environmental media, and they are potential parts that can be absorbed by organisms. The residue state $(\mathrm{V})$ is inert and inactive in a short time [34].

For coal gangue, the active state (I+II) and inert state $(\mathrm{V})$ of $\mathrm{U}$ element account for $35.43 \%$ and $39.02 \%$, respectively, on average. The active state (I+II) and inert state (V) of Th elements accounted for $22.80 \%$ and $46.74 \%$, respectively, on average. Therefore, compared with Th, the export capacity of $\mathrm{U}$ element in coal gangue is stronger. For three soil profiles, the active state of $\mathrm{U}(\mathrm{I}+\mathrm{II})$ is between $33.20 \%$ and $45.17 \%$, with an average of $37.34 \%$. The potential active state (III+IV) ranged from $51.67 \%$ to $62.58 \%$, with an average of $56.05 \%$. Inert state $(\mathrm{V})$ accounts for the lowest proportion, averaging $6.61 \%$ (Figure $7 \mathrm{a}$ ). Therefore, the active state of $U$ in the soil is greatly influenced by the output of the external source (coal gangue), and it is easy to form a realistic influence on the environment. Compared with $\mathrm{U}$, the content of active state (I+II) of Th element is generally lower, ranging from $13.47 \%$ to $21.57 \%$, with an average of $18.50 \%$ (Figure $7 \mathrm{~b}$ ). The proportion of inert state $(\mathrm{V})$ is relatively high, ranging from $39.46 \%$ to $64.37 \%$, with an average of $51.66 \%$, and the farther away from the coal gangue pile, the higher the proportion of inert state (V). Therefore, compared with $\mathrm{U}$ element, the active state of Th in soil is generally affected by the output of external sources (coal gangue), which may have a potential impact on the environment.
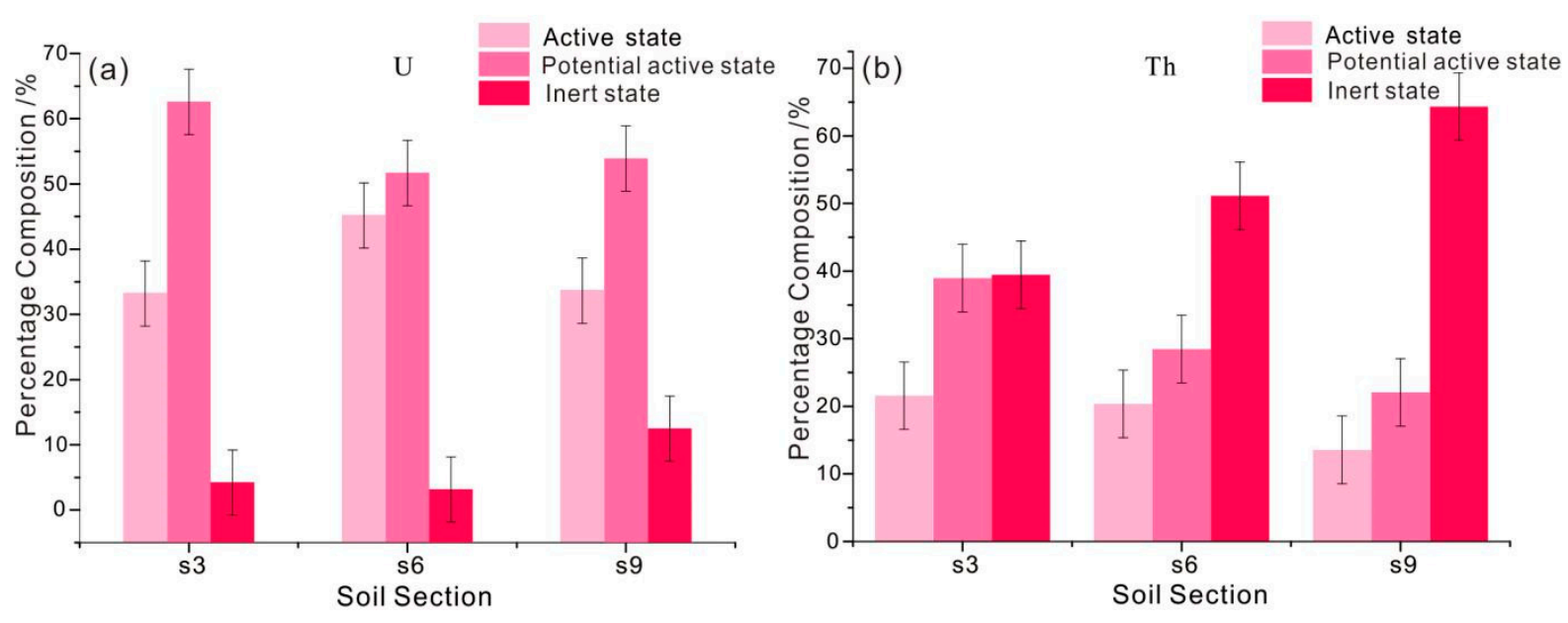

Figure 7. (a) Ecological activities of $U$ and (b)Th elements in different soil profiles.

\section{Conclusions}

Through this study, the potential ecological risk assessment of radioactive elements in surrounding soil caused by coal gangue stacking in small-scale sites was deeply understood. The sample collection scheme was designed, and the mineral composition of coal gangue, 
the content and the modes of occurrence for radioactive elements in coal gangue and soil profile samples were analyzed by qualitative-semi-quantitative method. Combined with the evaluation scheme of the index of geo-accumulation, the influence range of radioactive elements in coal gangue was comprehensively evaluated, and the potential ecological risks of small-scale coal gangue stacking were discussed. The main conclusions are as follows: (1) The results of mineral analysis show that the coal gangue in the study area is mainly clay mineral (kaolinite), and there are differences among different coal gangue, including calcite, dickite, and siderite. (2) The specific activity of radioactive elements in soil is much lower than that of coal gangue, and decreases gradually with the increase of depth. When reaching a certain distance, the radioactive content also decreases gradually with the increase of distance. The contamination halo range is limited $(\leq 30 \mathrm{~m})$. (3) $U$ and Th in coal gangue exist in the form of residue, $\mathrm{U}$ in soil mainly exists in the form of carbonate and organic combination, and Th in soil mainly exists in the form of residue and $\mathrm{Fe}-\mathrm{Mn}$ combination. (4) According to the evaluation method of the index of geo-accumulation, Th is easier to accumulate in the soil environment, but the pollution of Th and $U$ in soil is not obvious. (5) The active state of $U$ in soil is greatly influenced by the output of exogenous coal gangue, which is easy to form a realistic influence on the environment; the active state of Th is generally affected by the output of external sources (coal gangue), which may have potential impact on the environment.

Author Contributions: Conceptualization and writing—original draft preparation, D.W.; formal analysis, M.W. and Y.W.; methodology, G.H.; investigation, X.H.; software, C.W., writing-review and editing, W.F. All authors have read and agreed to the published version of the manuscript.

Funding: This research was funded by the Key Research and Development Projects in Anhui Province (201904a07020071), the National Key Basic Research and Development Program of China (2016YFC0201600), and the National Natural Science Foundation of China (No. 41502152).

Institutional Review Board Statement: Not applicable.

Informed Consent Statement: Not applicable.

Data Availability Statement: No new data were created or analyzed in this study. Data sharing is not applicable to this article.

Conflicts of Interest: The authors declare no conflict of interest.

\section{References}

1. Wang, M.; Gui, H.; Hu, R.; Zhao, H.; Li, J.; Yu, H.; Fang, H. Hydrogeochemical Characteristics and Water Quality Evaluation of Carboniferous Taiyuan Formation Limestone Water in Sulin Mining Area in Northern Anhui, China. Int. J. Environ. Res. Public Heal. 2019, 16, 2512. [CrossRef] [PubMed]

2. Liu, F.; Liu, S.; Chen, L.; Wang, C.; Liao, H.; Wu, Y.; Wang, N. Investigation and analysis of the content of natural radionuclides at coal mines in China. Radiat. Prot. 2007, 171-180. (In Chinese)

3. Walencik-Łata, A.; Smołka-Danielowska, D. 234U, 238U, 226Ra, 228Ra and 40K concentrations in feed coal and its combustion products during technological processes in the Upper Silesian Industrial Region, Poland. Environ. Pollut. 2020, 267, 115462. [CrossRef] [PubMed]

4. Turhan, Ş.; Gören, E.; Garad, A.; Altıkulaç, A.; Kurnaz, A.; Duran, C.; Özdemir, A. Radiometric measurement of lignite coal and its by-products and assessment of the us bility of fly ash as raw materials in Turkey. Radiochim. Acta. 2018, 106, 611-621. [CrossRef]

5. Guillén, J.; Muñoz-Serrano, A.; Baeza, A.S.; Salas, A. Speciation of naturally occurring radionuclides in Mediterranean soils: Bioavailabilty assessment. Environ. Sci. Pollut. Res. 2017, 25, 6772-6782. [CrossRef] [PubMed]

6. Pappa, F.; Tsabaris, C.; Patiris, D.; Eleftheriou, G.; Ioannidou, A.; Androulakaki, E.; Vlastou, R. Temporal investigation of radionuclides and heavy metals in a coastal mining area at Ierissos Gulf, Greece. Environ. Sci. Pollut. Res. 2019, 26, 27457-27469. [CrossRef]

7. Carvalho, F.; Oliveira, J.; Malta, M. Radioactivity in Iberian Rivers with uranium mining activities in their catchment areas. Procedia Earth Planet. Sci. 2014, 8, 48-52. [CrossRef]

8. Zhou, C.; Liu, G.; Cheng, S.; Fang, T.; Lam, P. The Environmental Geochemistry of Trace Elements and Naturally Radionuclides in a Coal Gangue Brick-Making Plant. Sci. Rep. 2014, 4, srep06221. [CrossRef] 
9. Habib, M.; Basuki, T.; Miyashita, S.; Bekelesi, W.; Nakashima, S.; Techato, K.; Phoungthong, K. Assessment of natural radioactivity in coals and coal combustion residues from a coal-based thermoelectric plant in Bangladesh: Implications for radiological health hazards. Environ. Monit. Assess. 2019, 191, 1-20.

10. Habib, M.; Basuki, T.; Miyashita, S.; Bekelesi, W.; Nakashima, S.; Phoungthong, K.; Techato, K. Distribution of naturally occurring radionuclides in soil around a coal-based power plant and their potential radiological risk assessment. Radiochim. Acta. 2019, 107, 243-259. [CrossRef]

11. Kříbek, B.; Sracek, O.; Mihaljevič, M.; Knésl, I.; Majer, V. Geochemistry and environmental impact of neutral drainage from an uraniferous coal waste heap. J. Geochem. Explor. 2018, 191, 1-21. [CrossRef]

12. Noli, F.; Tsamos, P. Seasonal variations of natural radionuclides, minor and trace elements in lake sediments and water in a lignite mining area of North-Western Greece. Environ. Sci. Pollut. Res. 2017, 25, 12222-12233. [CrossRef] [PubMed]

13. Chałupnik, S.; Wysocka, M.; Janson, E.; Chmielewska, I.; Wiesner, M. Long term changes in the concentration of radium in discharge waters of coal mines and Upper Silesian rivers. J. Environ. Radioact. 2017, 171, 117-123. [CrossRef] [PubMed]

14. Luneva, E. Radionuclides in Surface Waters, Bottom Sediments, and Hydrobionts in the Neman River. Inland Water Biol. 2018, 11, 97-102. [CrossRef]

15. Tessier, A.; Campbell, P.G.C.; Bisson, M. Sequential extraction procedure for the speciation of particulate trace metals. Anal. Chem. 1979, 51, 844-851. [CrossRef]

16. Hu, G.; Liu, G.; Wu, D.; Fu, B. Geochemical behavior of hazardous volatile elements in coals with different geological origin during combustion. Fuel 2018, 233, 361-376. [CrossRef]

17. Muller, G. Index of Geoaccumulation in Sediments of the Rhine River. Geo J. 1969, 2, 109-118.

18. Allard, T.; Ildefonse, P.; Beaucaire, C.; Calas, G. Structural chemistry of uranium associated with Si, Al, Fe gels in a granitic uranium mine. Chem. Geol. 1999, 158, 81-103. [CrossRef]

19. Zhu, B.; Sun, Y.; Xie, C. Spectroscopic study on Xingyi coal gangue in Guizhou under different calcination temperatures. J. China Coal Soc. 2008, 33, 1049-1052. (In Chinese)

20. Bu, N.; Liu, X.; Song, S.; Liu, J.; Yang, Q.; Li, R.; Zheng, F.; Yan, L.; Zhen, Q.; Zhang, J. Synthesis of NaY zeolite from coal gangue and its characterization for lead removal from aqueous solution. Adv. Powder Technol. 2020, 31, 2699-2710. [CrossRef]

21. Li, T. Study on Geochemical Characteristics and Utilization of Coal Gangue in Huainan Mining Area; University of Science and Technology of China: Hefei, China, 2015. (In Chinese)

22. Chen, Y.; Li, S.; Zhou, C. Material Composition Features and Reclaim Evaluation of Coal Gangue in Huainan Mining Area. Coal Geol. China 2011, 23, 20-23. (In Chinese)

23. Marziali, L.; Valsecchi, L.; Schiavon, A.; Mastroianni, D.; Viganò, L. Vertical profiles of trace elements in a sediment core from the Lambro River (northern Italy): Historical trends and pollutant transport to the Adriatic Sea. Sci. Total. Environ. 2021, $782,146766$. [CrossRef]

24. Abiriga, D.; Vestgarden, L.; Klempe, H. Groundwater contamination from a municipal landfill: Effect of age, landfill closure, and season on groundwater chemistry. Sci. Total. Environ. 2020, 737, 140307. [CrossRef]

25. Liu, L.; Huang, L.; Huang, R.; Lin, H.; Wang, D. Immobilization of heavy metals in biochar derived from co-pyrolysis of sewage sludge and calcium sulfate. J. Hazard. Mater. 2021, 403, 123648. [CrossRef]

26. Finkelman, R.; Palmer, C.; Wang, P. Quantification of the modes of occurrence of 42 elements in coal. Int. J. Coal Geol. 2018, 185, 138-160. [CrossRef]

27. Li, C.; Zheng, L.; Jiang, C.; Chen, X.; Ding, S. Characteristics of leaching of heavy metals from low-sulfur coal gangue under different conditions. Int. J. Coal Sci. Technol. 2021, 2021, 1-10. [CrossRef]

28. Liu, G.; Zhang, H.; Gao, L.; Zheng, L.; Peng, Z. Petrological and mineralogical characterizations and chemical composition of coal ashes from power plants in Yanzhou mining district, China. Fuel Process. Technol. 2004, 85, 1635-1646. [CrossRef]

29. Veerasamy, N.; Murugan, R.; Kasar, S.; Inoue, K.; Kavasi, N.; Balakrishnan, S.; Arae, H.; Fukushi, M.; Sahoo, S. Geochemical characterization of monazite sands based on rare earth elements, thorium and uranium from a natural high background radiation area in Tamil Nadu, India. J. Environ. Radioact. 2021, 232, 106565. [CrossRef] [PubMed]

30. Braun, J.; Pagel, M.; Herbilln, A.; Rosin, C. Mobilization and redistribution of REEs and thorium in a syenitic lateritic profile: A mass balance study. Geochim. Et Cosmochim. Acta 1993, 57, 4419-4434. [CrossRef]

31. Samouhos, M.; Godelitsas, A.; Nomikou, C.; Taxiarchou, M.; Tsakiridis, P.; Zavašnik, J.; Gamaletsos, P.; Apostolikas, A. New insights into nanomineralogy and geochemistry of Ni-laterite ores from central Greece (Larymna and Evia deposits). Geochemistry 2019, 79, 268-279. [CrossRef]

32. Yu, X.; Song, Y.; Wei, G.; Yu, G.; Gao, Y.; Xiao, F.; Ma, M. Pollution Characteristics of U and Th in Soil and Plant Screening in Light Rare Earth Tailings. Environ. Sci. Technol. 2020, 43, 26-30. (In Chinese)

33. Martínez-Aguirre, A.; León, M.; Ivanovich, M. U and Th speciation in river sediments. Sci. Total. Environ. 1995, 173-174, 203-209. [CrossRef]

34. Guo, P.; Duan, T.; Song, X.; Chen, H. Evaluation of a sequential extraction for the speciation of thorium in soils from Baotou area, Inner Mongolia. Talanta 2007, 71, 778-783. [CrossRef] [PubMed] 